Revue bibliographique pour le domaine irano-aryen

\title{
Rika Gyselen. « Sasanidische Siegelsteine de P. Horn et G. Steindorff revisité »
}

Julien Cuny

\section{(2) OpenEdition \\ 1 Journals}

\section{Édition électronique}

URL : http://journals.openedition.org/abstractairanica/46330

DOI : 10.4000/abstractairanica.46330

ISBN : 1961-960X

ISSN : 1961-960X

Éditeur :

CNRS (UMR 7528 Mondes iraniens et indiens), Éditions de l'IFRI

Référence électronique

Julien Cuny, «Rika Gyselen. "Sasanidische Siegelsteine de P. Horn et G. Steindorff revisité » », Abstracta Iranica [En ligne], Volume 37-38-39 | 2018, document 43, mis en ligne le 30 décembre 2018, consulté le 02 octobre 2020. URL : http://journals.openedition.org/abstractairanica/46330 ; DOI : https://doi.org/10.4000/abstractairanica.46330

Ce document a été généré automatiquement le 2 octobre 2020.

Tous droits réservés 


\title{
Rika Gyselen. « Sasanidische Siegelsteine de P. Horn et G. Steindorff revisité »
}

\author{
Julien Cuny
}

\section{RÉFÉRENCE}

Rika Gyselen. « Sasanidische Siegelsteine de P. Horn et G. Steindorff revisité » in R. Gyselen (ed.). Words and symbols: Sasanian Objects and the Tabarestān Archive. Bures-surYvette : Groupe pour l'Étude de la Civilisation du Moyen-Orient, 2016, p. 27-106 (Res Orientales, XXIV)

1 L'A. livre une utile mise à jour du catalogue de la collection des sceaux sassanides des musées de Berlin, particulièrement pour la translittération et la lecture des inscriptions, et une bibliographie réactualisée, et accompagnée d'annexes facilitant grandement le travail de recherche. C'est également l'occasion d'une introduction méthodologique sur la notion de modèle, appuyée de quelques exemples, que l'A. a souhaité ajouter à la réflexion inspirée en 2014 par P. Callieri lors de ses leçons au Collège de France (cf. c.r. de Callieri, Architecture et représentation dans l'Iran sassanide, Cahier de Studia Iranica 50 dans ce volume). 


\section{AUTEURS}

\section{JULIEN CUNY}

Conservateur au Musée du Louvre, Paris 